\title{
Anticoagulation in Patients Aged $\geq 75$ years with Atrial Fibrillation: Role of Novel Oral Anticoagulants
}

\author{
Kuan H. Ng • Robert G. Hart • John W. Eikelboom
}

To view enhanced content go to www.cardiologytherapy-open.com

Received: April 17, 2013 / Published online: August 6, 2013

(C) The Author(s) 2013. This article is published with open access at Springerlink.com

\section{ABSTRACT}

Atrial fibrillation (AF) is an important cause of preventable, disabling stroke and is increasingly prevalent with advancing age. As life expectancies increase around the world, AFrelated stroke is a growing global public health concern. Most AF patients are elderly ( $\geq 75$ years old) and increasing age is a consistent independent risk factor for AF-associated stroke. Warfarin anticoagulation is highly effective for stroke prevention in AF patients, but is underutilized especially in the elderly. Although elderly patients are at increased risk of hemorrhage with oral anticoagulants, the benefit for ischemic stroke reduction exceeds

K. H. Ng ( $(\varangle)$ · R. G. Hart · J. W. Eikelboom Department of Medicine (Stroke Program), Population Health Research Institute, McMaster University and Hamilton Health Sciences,

237 Barton Street East, Hamilton,

ON L8L 2X2, Canada

e-mail: kelvin.ng@phri.ca

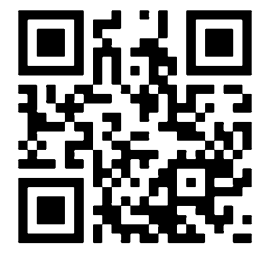

Enhanced content for this article is

available on the journal web site:

www.cardiologytherapy-open.com the risk of hemorrhage for most elderly patients. Consequently, age alone should not be considered a contraindication for anticoagulation. Novel oral anticoagulants such as dabigatran, rivaroxaban and apixaban are at least as effective as warfarin in preventing strokes in patients with AF. Relative to warfarin, these novel agents reduce the risk of intracranial hemorrhage, the most devastating complication of anticoagulation therapy in elderly AF patients. The novel oral anticoagulants are especially appealing for stroke prevention in elderly patients with AF.

Keywords: Age; Anticoagulation; Apixaban; AF; Bleeding; Dabigatran; Novel oral anticoagulants; Rivaroxaban; Stroke; Stroke prevention; Warfarin

\section{INTRODUCTION}

Atrial fibrillation (AF) is a major risk factor for disabling ischemic stroke due to embolism from the left atrial appendage. The prevalence of AF increases with increasing age (Fig. 1) [1]. The true prevalence of AF is difficult to assess, as 


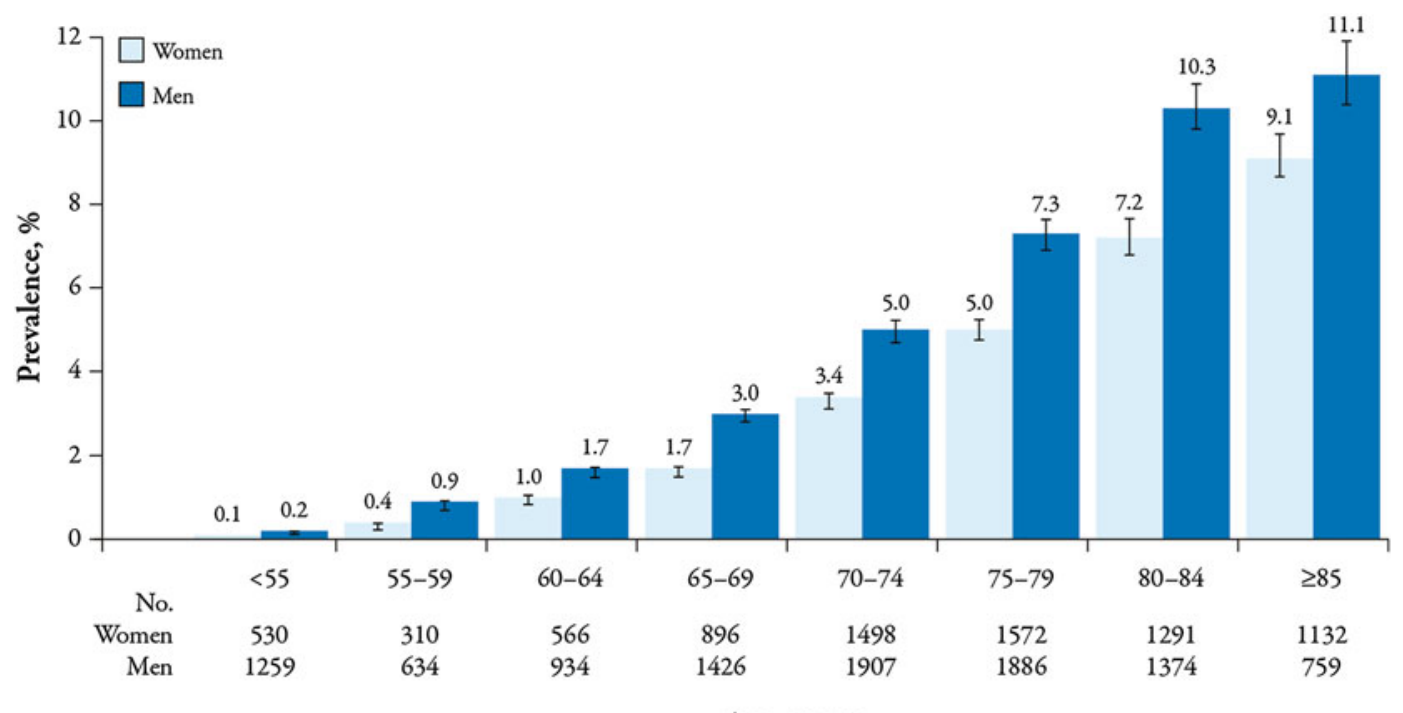

Age, years

Fig. 1 Prevalence of AF with increasing age [1]. Error bars indicate $95 \%$ confidence intervals. Numbers indicate number of men and women with atrial fibrillation in each category. Adapted from Go et al. [1]

a significant proportion of patients will be asymptomatic or have subclinical disease; however, it is estimated that at least $10 \%$ of elderly people ( $\geq 75$ years old) have AF [2] and $56 \%$ of people with the condition are elderly [3, 4]. The influence of AF on health increases with age, and $71 \%$ of strokes that occur in patients with AF are in those aged over 70 years [5]. The outcome of patients following stroke due to AF is worse, on average, compared with non-AFrelated strokes [6].

Antiplatelet agents and oral anticoagulants are effective in reducing the risk of stroke in AF patients, with oral anticoagulants being more effective in reducing the risk of ischemic strokes than antiplatelet agents [7]. However, increasing age is associated with underutilization of warfarin [8]. Clinical data on elderly patients are limited as they are often underrepresented in randomized controlled trials (RCTs). Furthermore, older patients have an increased risk of hemorrhage and often have multiple comorbidities including chronic kidney disease (CKD), anemia, hypertension, diabetes and an increased risk of falls.

In recent years, novel selective oral anticoagulants have become available. All undergo substantial renal excretion [9], but are at least as effective as adjusted-dose warfarin in reducing the risk of stroke. They are also associated with a decreased risk of intracranial hemorrhage in patients with AF [10-12]. While it is likely that the new generation of novel oral anticoagulants will eventually replace warfarin, the role of these agents in the elderly remains to be fully defined. This review examines the use of novel oral anticoagulants in patients aged $\geq 75$ years with $\mathrm{AF}$, focusing on information from randomized trials. In addition, the relationship between age, AF and stroke risk, as well as the current evidence for oral anticoagulants and antiplatelet agents for stroke prevention in the elderly, will be considered. 


\section{METHODS}

This review article incorporates data from observational studies, review articles, available guidelines and RCTs on the use of anticoagulants and antiplatelet agents for stroke prevention in elderly patients. Relevant literature was obtained with a MEDLINE search. The literature was chosen based on their inclusion and influence on current practice.

\section{DISCUSSION}

\section{Age and AF}

$\mathrm{AF}$ is the most common clinically significant arrhythmia and is associated with significant mortality and morbidity [13]. The number of patients with AF is forecast to increase as will the proportion of elderly patients [1]. Adjusting for age, risk factors for AF include valvular heart disease, congestive heart failure, diabetes and hypertension, all of which are more common in the elderly.

AF independently increases stroke risk by fivefold in the general population and accounts for a greater proportion of strokes with increasing age [5]. The risk of thromboembolism in AF increases sharply with age over 65 years, with the relative risk increasing approximately 1.45 -fold per decade [7]. Age is a strong and consistent predictor of stroke in patients with AF and is included in all stroke risk stratification schemes for AF [14, 15]. While increasing age as a risk factor for AF and stroke is continuous, age $\geq 75$ years is arbitrarily used to dichotomize risk in cohort analyses and systematic reviews [16].

Other independent risk factors for stroke include previous transient ischemic attacks or stroke, heart failure, hypertension and diabetes.
The Congestive cardiac failure, Hypertension, Age $\geq 75$, Diabetes and previous Stroke or transient ischemic attack $\left(\mathrm{CHADS}_{2}\right)$ score is a simple, commonly used stroke risk stratification scheme for patients with AF [17]. It was developed by incorporating the Stroke Prevention in AF (SPAF) and AF Investigators (AFI) risk schemes and was validated in a cohort of patients with AF admitted to hospital [18-20] (Table 1). Most guidelines now recommend the use of vitamin $\mathrm{K}$ antagonists in patients with a $\mathrm{CHADS}_{2}$ score of 1 or greater. However, the recommendations have to be balanced against the risk of hemorrhage, which is higher during anticoagulation in the elderly.

Table 1 Comparison of CHADS2 and HAS-BLED scores [18-20]

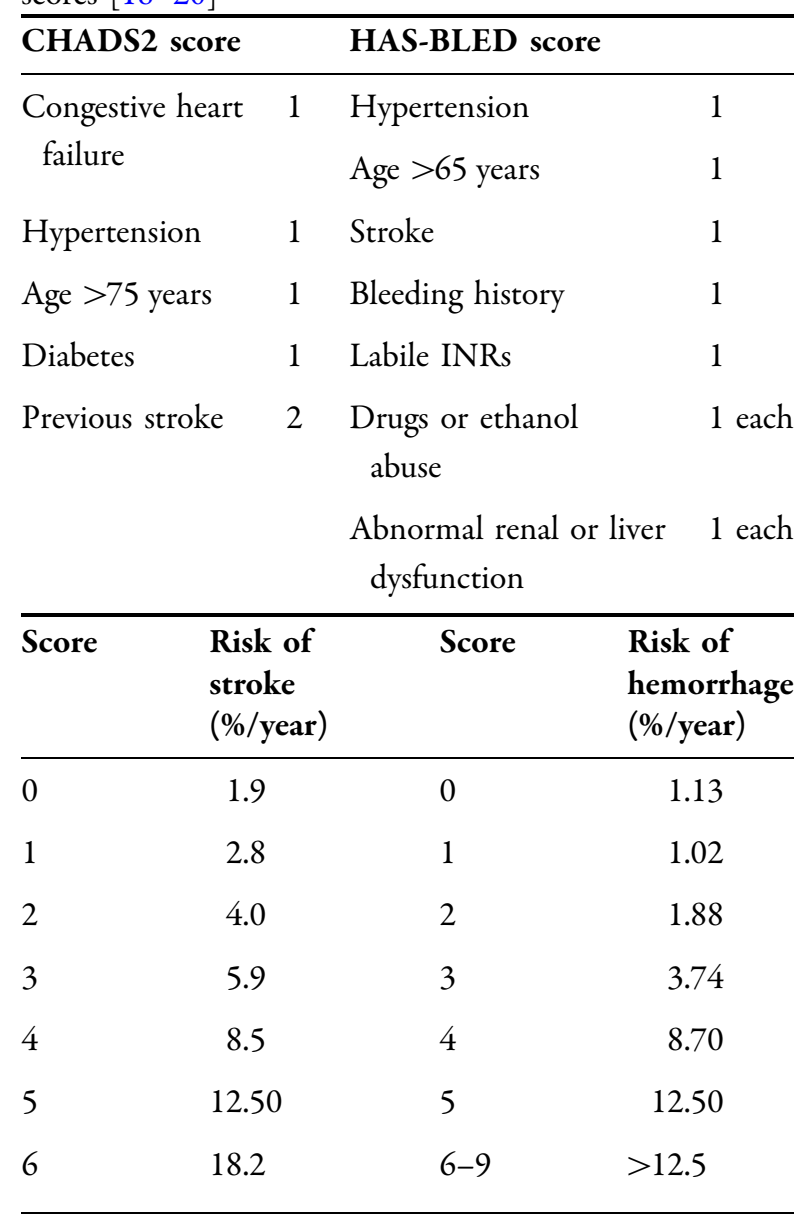




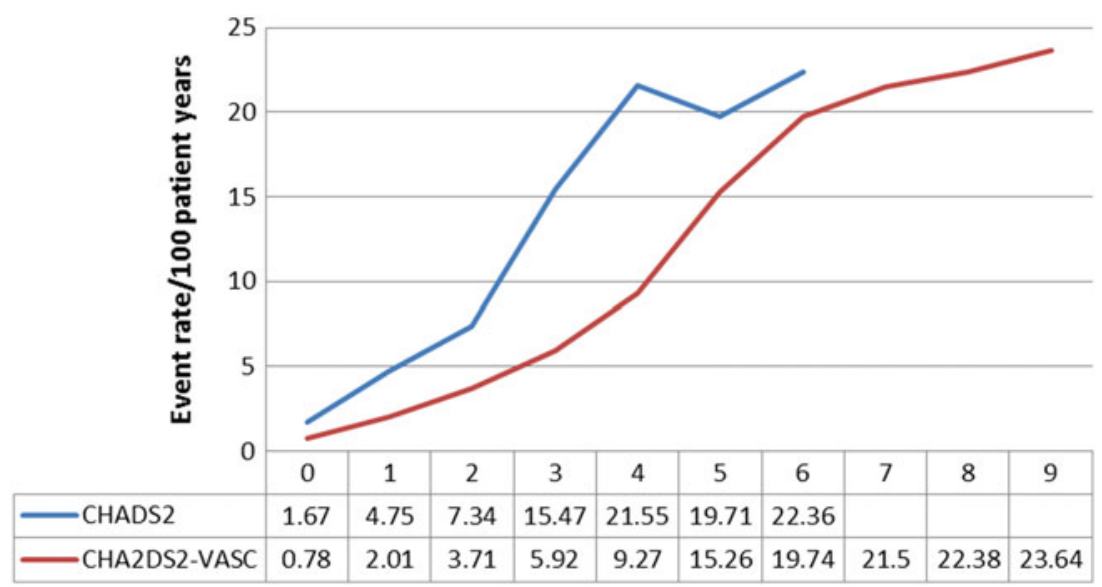

Fig. 2 Comparative rate of death, stroke and systemic embolism between $\mathrm{CHADS}_{2}$ versus $\mathrm{CHA}_{2} \mathrm{DS}_{2}-\mathrm{VASc}_{\mathrm{C}}[15,22]$

The Congestive cardiac failure, Hypertension, Age $\geq 75$, Diabetes and previous Stroke or transient ischemic attack, Vascular disease, Age 65-74 and Sex score $\left(\mathrm{CHA}_{2} \mathrm{DS}_{2}\right.$-VASc) has been proposed as an improvement over $\mathrm{CHADS}_{2}$, specifically for stratifying risk in patients under the age of 75 years, who do not have any of the $\mathrm{CHADS}_{2}$ risk factors for stroke [21, 22]. In addition to the risk factors identified in the $\mathrm{CHADS}_{2}$ score, $\mathrm{CHA}_{2} \mathrm{DS}_{2}$-VASc incorporates one point each for sex, history of vascular disease and age $\geq 65$ years. Age $\geq 75$ years will incur an extra point.

Female sex is incorporated into $\mathrm{CHA}_{2} \mathrm{DS}_{2}$ VASc as an independent predictor of stroke in AF despite the absence of a clear biologically plausible explanation for the underlying etiology. Large differences in stroke risk between the sexes were noted in the AFI metaanalysis in 1990 [23] and were consistent with large observational studies [24-26]. The difference in stroke risk between the sexes was greatest with increasing age. Elderly women had a significantly higher risk of stroke compared with similarly aged men [24].

The additional components within $\mathrm{CHA}_{2} \mathrm{DS}_{2}$-VASc compared with $\mathrm{CHADS}_{2}$ was shown to improve discrimination in patients with a $\mathrm{CHADS}_{2}$ score of 1 by identifying patients aged $<75$ years with sufficiently low absolute stroke risk who may not be expected to benefit from anticoagulant therapy [15, 22] (Fig. 2). Conversely, all patients aged $\geq 75$ years would be considered for anticoagulation, as the additional point for older age would give a $\mathrm{CHA}_{2} \mathrm{DS}_{2}$-VASc score of at least $2[27,28]$.

Renal function declines gradually with age and CKD is common in patients with AF. Onethird of all outpatients with AF and over 50\% of elderly patients with AF have CKD (estimated glomerular filtration rate (eGFR) $<60 \mathrm{ml} / \mathrm{min})[29,30]$. CKD is an independent predictor of stroke risk in patients with AF (HR 1.5) $[29,31,32]$ and the impact of Stage 3 CKD on stroke risk is similar to other predictors used in the $\mathrm{CHADS}_{2}$ score [14]. However, the precise mechanisms underlying increased stroke risk in CKD are unclear and have not been incorporated into any of the commonly used risk stratification scores. There are less data stratifying stroke risk in Stage 4 CKD and end stage renal failure, but $\mathrm{AF}$ remains an independent risk factor for ischemic stroke [33]. 


\section{Warfarin in Elderly Patients with AF}

Most ischemic strokes in patients with AF are due to cardiogenic embolism from thrombi originating from the left atrial appendage; however, up to $25 \%$ of cases may be caused by intrinsic small vessel cerebrovascular disease with co-existing vascular risk factors such as coronary artery disease, hypertension and diabetes [34]. Aspirin appears to exert most of its effect via prevention of non-cardiogenic embolic events, while warfarin is far superior to aspirin in preventing cardio-embolic ischemic strokes [34]. At most, aspirin reduces the relative risk of stroke by about $25 \%$ in patients with AF. Most of the reduction in stroke risk with aspirin leads to a reduction in transient ischemic attacks and non-disabling strokes [35]. Dose-adjusted warfarin reduces the relative risk of stroke by about $60 \%$ in patients with AF compared with placebo [3, 28, 36]. With increasing age, the benefit of aspirin in preventing stroke decreases and appears to be ineffectual when patients enter their eighth decade, whereas the risk reduction derived from warfarin anticoagulation is preserved with age [7].

The most serious side effect of warfarin is bleeding, including intracranial bleeding. Age is an independent risk factor for bleeding on anticoagulant therapy [37, 38] and warfarin is associated with an increased risk of bleeding compared with aspirin therapy (HR 1.71) [39]. The absolute risk reduction of all strokes and cardiovascular events is not substantially offset by the proportionally smaller increased risk of hemorrhage in the general population. Elderly patients are likely to derive the greatest benefit from warfarin therapy, but have the highest risk of hemorrhage. Elderly patients are underrepresented in most RCTs assessing the use of warfarin in $\mathrm{AF}$, with patients aged $\geq 75$ years representing only $20 \%$ of patients in most RCTs involving oral anticoagulants in AF [40]. The exception is the Birmingham AF Trial in the Aged (BAFTA), which was restricted to AF patients $\geq 75$ years old with no contraindications to hemorrhage. BAFTA participants were randomized to warfarin versus aspirin, and there was no increased risk of major hemorrhage with anticoagulation. The rates of hemorrhage in BAFTA were lower when compared with a previous subgroup metaanalysis of anticoagulation in patients aged $\geq 75$ years. $40 \%$ of patients in BAFTA had already been established on warfarin and probably underestimated bleeding risk compared with warfarin-naïve patients [41].

\section{Prediction of Hemorrhage in Elderly Patients on Warfarin}

Several risk stratification scores have been developed to help predict hemorrhage during warfarin anticoagulation. The Hypertension, Abnormal liver/renal function, Stroke, Bleeding history or disposition, Labile International Normalized Ratio, Elderly, Drugs/alcohol (HAS-BLED) score has been incorporated in European and Canadian guidelines on the management of patients with AF $[19,20]$. The score is relatively easy to use and provided modest predictive value for major hemorrhage in patients on oral anticoagulants (C-statistic 0.69) in the Euro Heart Survey cohort [42]. However, HAS-BLED requires validation in other patient populations such as the elderly before it is adopted universally. Other bleeding risk prediction scores for warfarin anticoagulation have been proposed, but none have been adequately validated in our view [38, 43]. Many of the factors that predict hemorrhage in these risk prediction scores are also risk factors for stroke. 
Therefore, the use of risk stratification scores in elderly patients with AF is likely to be limited as a result (Table 1).

Based on CHA2DS2-VASc risk factors, men with no hypertension, diabetes or prior stroke but who had AF in the SPAF trials were at the lowest risk of stroke while on aspirin therapy, with a stroke rate of $1.6 \%$ /year (95\% CI 0.7-3.9) [7]. Men aged $\geq 75$ years participating in BAFTA and without other $\mathrm{CHA}_{2} \mathrm{DS}_{2}$-VASc risk factors had a stroke rate of $2.1 \%$ year (95\% CI 0.77-4.6) during aspirin therapy [27]. The margin of error for these rates is wide and includes rates that would warrant anticoagulation. Elderly women with AF carry a higher risk of stroke than elderly men [28]. It is unclear whether patients aged $\geq 75$ years with $\mathrm{AF}$ who are at low risk can be reliably identified.

\section{Randomized Trials Comparing Warfarin Versus Aspirin in Patients with AF Aged $\geq 75$ years}

A meta-analysis of randomized trials, including 29 trials involving 28,044 patients with a mean age of 71 years, confirmed the superiority of warfarin over anti-platelet agents in reducing stroke risk. The absolute increase in major extracranial hemorrhage on warfarin compared with aspirin was overshadowed by the absolute reduction in stroke risk in patients with AF [44]. However, only 2,680 (10\%) participants in these randomized trials were $\geq 75$ years old despite the fact that most patients with AF were within this age group. However, based on the AFI pooled meta-analysis from six trials [39] and the results of BAFTA [45], it is clear that warfarin anticoagulation reduces the risk of stroke to a greater extent than aspirin in elderly patients with AF (Table 2) [46, 47].

In BAFTA, elderly patients on oral anticoagulants had a $52 \%$ relative risk reduction in all strokes or systemic embolism compared with aspirin and had no significant increase in intracranial or extracranial hemorrhage [45]. The risk of major hemorrhage was lower than that noted in the AFI pooled meta-analysis [39]. This may be explained by the use of a contemporary International Normalized Ratio (INR) target range of $2-3$. In addition, $40 \%$ of patients in BAFTA were not warfarin naïve and were already established on warfarin prior to enrollment compared with the warfarin-naïve

Table 2 Absolute stroke rate in AF patients $\geq 75$ years old and effect of anticoagulation

\begin{tabular}{lrllll}
\hline Trial & $N$, aspirin & $\begin{array}{l}\text { Stroke rate on } \\
\text { aspirin (\%/year) }\end{array}$ & Anticoagulant & $\begin{array}{l}\text { Relative risk } \\
\text { reduction by } \\
\text { anticoagulant }\end{array}$ & $\begin{array}{l}\text { NNT for } \\
\text { 1 year }\end{array}$ \\
\hline AF Investigators (2002) [39] & 855 & $5.9 \% /$ year $^{\mathrm{a}}$ & Warfarin & $0.37^{\#}$ & 46 \\
BAFTA (2007) [45] & 485 & $4.9 \% /$ year & Warfarin & $0.52^{\#}$ & 40 \\
ACTIVE A (2009) [46] & $\sim 1,550$ & $4.4 \% /$ year & NA & NA & NA \\
AVERROES (2011) [47] & $\sim 950$ & $6.1 \% /$ year & Apixaban & $0.67^{\#}$ & 24 \\
\hline
\end{tabular}

$N$ number of participants, $N N T$ number needed to treat, $N A$ not applicable

In addition, the observational cohort ATRIA study reported an ischemic stroke rate of 3.2\%/year among 2,313 AF patients $\geq 75$ years who were not taking warfarin [1]

a Restricted to ischemic strokes

\# Statistically significant reduction with $p$ value $<0.05$ 
cohorts in the other studies included in the AFI pooled meta-analysis. This observation is supported by other recent warfarin inception studies in which elderly patients had an increased risk of hemorrhage in the first year of treatment [41, 48]. Once established on treatment and monitored closely, warfarin is safe in elderly patients with AF.

Current guidelines support the use of oral anticoagulation therapy in all patients $\geq 75$ years for the prevention of ischemic stroke $[3,28]$. Despite this, the uptake of oral anticoagulants among patients $\geq 75$ years remains low. In our view, all patients with $\mathrm{AF}$ $\geq 75$ years old (and especially women) should be considered for anticoagulation prophylaxis to prevent stroke in the absence of any clear contraindications, provided it can be initiated and monitored safely [7]. From the data summarized above, the risk of stroke for these patients is sufficiently high and the efficacy of warfarin is established.

\section{Challenges with Warfarin Anticoagulation in Elderly Patients with AF}

While all patients aged $\geq 75$ years should be considered for warfarin anticoagulation, the decision to prescribe warfarin for an individual patient should take into consideration risk of stroke versus hemorrhage, practicalities for monitoring anticoagulation and patient preference $[49,50]$. Furthermore, patients with $\mathrm{AF}$ aged $\geq 75$ years are more likely to experience significant co-morbidities on multiple medications.

\section{Time in Therapeutic Range on Warfarin Anticoagulation}

Limitations of vitamin $\mathrm{K}$ antagonists for stroke prevention include their narrow therapeutic window, which requires regular blood monitoring for assessment of INR and dosage adjustments. The optimal therapeutic range for anticoagulation with warfarin in non-valvular $\mathrm{AF}$ is between 2 and 3 . Higher intensity anticoagulation with INRs of greater than 3 are associated with double the risk of intracranial hemorrhage compared with patients who are not on warfarin [51-53]. The risk of intra-cerebral hemorrhage is higher with advancing age [54]. Conversely, a target INR of less than 2 confers no further reduction in hemorrhage risk compared with an INR of 2-3 [52]. Attaining an INR $>2$ is associated with not just lower risk of stroke, but also reduced stroke severity and fewer deaths [51].

Older patients are more sensitive to warfarin and require lower dosages to achieve a target INR range [55]. In addition, older patients are more likely to be on multiple medications with frequent INR fluctuations due to ill health, poor diet and issues with compliance, which may ultimately result in less time within the therapeutic INR range compared with younger patients. Closer monitoring of anticoagulation may be merited in elderly patents. The highest risk of major bleeding during warfarin anticoagulation is in the first 12 months after treatment initiation. Subsequently, warfarinexperienced patients are at lower risk of hemorrhage and stroke compared with warfarin-naïve patients [45].

\section{Risk of Falls}

Other risk factors for intracranial hemorrhage in the elderly are an increased risk of falls and associated neuropsychiatric disease [38, 56]. Risk of falls and intra-cerebral hemorrhage with warfarin are often quoted as a reason to avoid anticoagulation. However, if a patient has a $5 \%$ annual risk of stroke from $\mathrm{AF}$, it has been estimated that the patient would need to fall over 295 times to offset the benefit of oral 
anticoagulants [57]. The association between intracranial hemorrhage and neuropsychiatric disease is multifactorial in nature and may be more a reflection of impairment of functional status. Psychotropic medications, poor compliance with medication and associated alcohol use may all contribute to the increased risk of falls in patients with neuropsychiatric disease. Patients with Alzheimer's dementia may be predisposed to intracranial hemorrhage if they have amyloid angiopathy or apolipoprotein E polymorphisms. However, quantification of the risk and application to decision-making regarding anticoagulation in this setting have not been clearly defined.

\section{Chronic Kidney Disease and Anemia}

The prevalence of renal disease increases with advancing age [30]. Patients with CKD have three times the risk of AF compared with patients without CKD and are likely to be on warfarin anticoagulation. However, stage $3 \mathrm{CKD}$ is associated with twice the rate of major bleeding during warfarin anticoagulation [12, 58]. These higher rates of major bleeding were not adjusted for age. In a longitudinal cohort analysis, stage 3 CKD was not an independent predictor of hemorrhage during warfarin anticoagulation [59]. While the Anticoagulation and Risk Factors In AF (ATRIA) dataset showed CKD with an estimated creatinine clearance $(\mathrm{eCrCl})$ of $<30 \mathrm{ml} / \mathrm{min}$ was an independent predictor of major hemorrhage (HR 4.3, $p<0.001$ ), it has not been sufficiently validated for general clinical use [43]. Whist patients with CKD are at increased risk of anemia, the same ATRIA dataset concluded anemia (hemoglobin $<13 \mathrm{~g} / \mathrm{dl}$ in men; $<12 \mathrm{~g} / \mathrm{dl}$ in women) was an independent predictor of hemorrhage (HR 4.2, $p<0.001$ ) [43]. Anemia is prevalent in the elderly and is estimated to affect $23.9 \%$ of patients over the age of 70 years $[60,61]$.

\section{Patient Preferences for Anticoagulation}

The decision to take anticoagulation for $\mathrm{AF}$ requires consideration of the potential risks and benefits. Physicians and patients can differ in how they weigh up these factors when arriving at a decision to take oral anticoagulants. Patients at risk of developing AF, who have no previous history of stroke, place more value on the avoidance of stroke and less value on the avoidance of bleeding than physicians [62].

There is significant underuse of antithrombotic drugs in elderly patients with AF. Physicians may make strong recommendations for or against warfarin as a treatment, but patient preferences should be considered before making decisions about anticoagulation.

\section{Novel Selective Oral Anticoagulants for Elderly Patients with AF}

While warfarin has been established as the mainstay treatment for SPAF, novel anticoagulants have been introduced in the past few years, which are more selective in their anticoagulant mechanisms and easier to administer. Four novel anticoagulants (two direct thrombin inhibitors, ximelagatran and dabigatran, and two factor Xa inhibitors, apixaban and rivaroxaban) have been evaluated in large phase III randomized trials. Ximelagatran was withdrawn from the market in 2006 due to rare, but serious, hepatotoxicity. The other novel anticoagulants have not shown the same adverse effect. The four recent randomized trials testing the novel oral anticoagulants in AF patients included 21,062 participants $\geq 75$ years old and provide substantial evidence for their efficacy in this age group [10-12, 47] (Table 3).

Dabigatran, apixaban and rivaroxaban do not require regular anticoagulation monitoring 
Table 3 Comparison of novel oral anticoagulants in patients $\geq 75$ years

\begin{tabular}{|c|c|c|c|c|c|}
\hline $\begin{array}{l}\text { Novel } \\
\text { agent }\end{array}$ & Trial & $\begin{array}{l}\text { Intervention versus warfarin } \\
\text { unless specified }\end{array}$ & $\begin{array}{l}\text { Number of } \\
\text { participants } \\
\geq 75 \text { years }\end{array}$ & $\begin{array}{l}\text { Hazard Ratio } \\
\text { for Stroke } \\
\text { Risk }\end{array}$ & $\begin{array}{l}\text { Hazard Ratio } \\
\text { for major } \\
\text { Hemorrhage }\end{array}$ \\
\hline \multirow[t]{2}{*}{ Dabigatran } & RE-LY [10] & Dabigatran $110 \mathrm{mg}$ bid & 7,258 & $0.88(0.66-1.17)$ & $1.01(0.83-1.23)$ \\
\hline & & Dabigatran $150 \mathrm{mg}$ bid & & $0.67(0.49-0.90)$ & $1.18(0.98-1.42)$ \\
\hline Rivaroxaban & $\begin{array}{l}\text { ROCKET-AF } \\
{[11]}\end{array}$ & $\begin{array}{c}\text { Rivaroxaban } 20 \mathrm{mg} \text { bid }(15 \mathrm{mg} \\
\text { od if } \mathrm{eCrCl} 30-49 \mathrm{ml} / \mathrm{min})\end{array}$ & 6,229 & $0.88(0.75-1.03)^{\mathrm{a}}$ & $1.04(0.90-1.20)^{\mathrm{a}}$ \\
\hline \multirow[t]{2}{*}{ Apixaban } & $\begin{array}{l}\text { ARISTOTLE } \\
{[12]}\end{array}$ & Apixaban $5 \mathrm{mg}$ bid & 5,678 & $0.79(0.65-0.95)^{\mathrm{b}}$ & $0.69(0.60-0.80)^{\mathrm{b}}$ \\
\hline & $\begin{array}{l}\text { AVERROES } \\
\text { [47] }\end{array}$ & $\begin{array}{l}\text { Apixaban } 5 \mathrm{mg} \text { bid }(2.5 \mathrm{mg} \text { bid if } \\
2 \text { out of } 3 \text { of the following criteria; } \\
\text { serum creatinine } \geq 133 \mathrm{ml} / \mathrm{min} \text {, age } \\
\geq 80 \text { years or weight } \leq 60 \mathrm{~kg} \text { ) vs. } \\
\text { Aspirin }\end{array}$ & 1,897 & $0.46(0.33-0.65)^{b}$ & $1.13(0.74-1.75)^{\mathrm{b}}$ \\
\hline
\end{tabular}

${ }^{a}$ Intention to treat analysis. Estimated from the entire group irrespective of age as no statistically significant interaction with age

b Estimated from the entire group irrespective of age as no statistically significant interaction with age

Table 4 Key pharmacological characteristics of novel anticoagulants

\begin{tabular}{|c|c|c|c|}
\hline \multirow[t]{2}{*}{ Feature } & \multicolumn{3}{|l|}{ Drug } \\
\hline & $\overline{\text { Dabigatran }}$ & Rivaroxaban & Apixaban \\
\hline Type of drug & Direct thrombin inhibitor & Factor $\mathrm{Xa}$ inhibitor & Factor $\mathrm{Xa}$ inhibitor \\
\hline Half-life (h) & $14-17$ & $7-11$ & $8-15$ \\
\hline Bioavailability (\%) & $\sim 6$ & $80-100$ & $34-88$ \\
\hline $\begin{array}{l}\text { Renal elimination } \\
(\%)\end{array}$ & $\sim 80$ & 33 & $\sim 22$ \\
\hline Dosage & $\begin{array}{l}150 \mathrm{mg} \text { bid }(110 \mathrm{mg} \text { bid if } \\
\text { patients at risk of bleeding or } \\
>80 \text { years of age })\end{array}$ & $\begin{array}{l}20 \mathrm{mg} \text { od }(15 \mathrm{mg} \text { od in } \\
\text { patients with } \mathrm{eCrCl} \\
15-49 \mathrm{ml} / \mathrm{min})\end{array}$ & $\begin{array}{l}5 \mathrm{mg} \text { bid }(2.5 \mathrm{mg} \text { bid in patients with } \\
\text { impaired renal function and }>80 \text { years } \\
\text { or }<60 \mathrm{~kg} \text { in weight }\end{array}$ \\
\hline $\begin{array}{l}\text { Age-related dosage } \\
\text { recommendations }\end{array}$ & $110 \mathrm{mg}$ bid if $>80$ years & None & $\begin{array}{l}2.5 \mathrm{mg} \text { bid if }>80 \text { years with serum } \\
\text { creatinine } \geq 1.5 \mathrm{mg} / \mathrm{dl}(133 \mu \mathrm{mol} / \mathrm{l})\end{array}$ \\
\hline $\begin{array}{c}T_{\max } \text { after oral } \\
\text { ingestion }(\mathrm{h})\end{array}$ & 1.5 & $2-4$ & $1.5-3.5$ \\
\hline
\end{tabular}

or frequent dose adjustments; however, a specific antidote to rapidly reverse the anticoagulant effect of these agents in the event of an acute hemorrhage is not available (other than acute hemodialysis for agents such as dabigatran) [63] (Table 4). These novel anticoagulant agents have been approved for clinical use and have been shown to be at least non-inferior to dose-adjusted warfarin for stroke prevention. 


\section{Dabigatran}

In the Randomized Evaluation of Long-term Anticoagulant TherapY (RE-LY) randomized trial, two doses of dabigatran $(110 \mathrm{mg}$ and $150 \mathrm{mg}$ twice daily) were compared with warfarin [10]. Both doses of dabigatran in RELY were associated with a lower risk of major hemorrhage in patients $<75$ years, but this was not the case in those aged $\geq 75$ years. The risk of major hemorrhage and extracranial hemorrhage rose more steeply with dabigatran than warfarin with increasing age. Dabigatran $150 \mathrm{mg}$ twice daily was associated with an increased risk of major extracranial bleeding in elderly patients compared with warfarin. However, the risk of intracranial bleeding remained lower with both doses of dabigatran with no evidence of interaction with age [64]. Dabigatran $150 \mathrm{mg}$ bid was associated with a lower risk of strokes or systemic embolism compared to warfarin and there was no association between dabigatran and the risk of myocardial infarctions [10]. As dabigatran is dependent on renal excretion, it is contraindicated in severe renal disease $(\mathrm{eCrCl}$ $<30 \mathrm{ml} / \mathrm{min}$ ). In the USA, only dabigatran $150 \mathrm{mg}$ bid is licensed for use in the prevention of strokes in patients with $\mathrm{AF}$, while in Canada and the UK dabigatran $110 \mathrm{mg}$ bid is also licensed for use in patients at increased risk of bleeding (older patients $>80$ years, eCrCl $30-60 \mathrm{ml} / \mathrm{min}$ or low body weight).

\section{Rivaroxaban}

In contrast to the other novel anticoagulants currently on the market, rivaroxaban is dosed daily (Table 4). Rivaroxaban is less dependent on renal excretion compared with dabigatran. Rivaroxaban was compared with warfarin in the Rivaroxaban Once Daily Oral Direct Factor Xa Inhibition Compared with vitamin $\mathrm{K}$
Antagonism for Prevention of Stroke and Embolism Trial in Atrial Fibrillation (ROCKETAF) study in patients at high risk of stroke and hemorrhage [11]. While patients with severe renal disease were excluded from the trial, patients with moderate renal function $(\mathrm{eCrCl}$ $30-49 \mathrm{ml} / \mathrm{min}$ ) were recruited and received a reduced dose of rivaroxaban (15 $\mathrm{mg}$ daily). There was no significant difference in stroke or systemic embolism on comparing the treatment effects of rivaroxaban versus warfarin in patients with or without reduced eCrCl [58]. The risk of intracerebral and fatal hemorrhages was lower with rivaroxaban compared with warfarin. However, there was an increased risk of non-major clinically relevant bleeding in patients aged $\geq 75$ years treated with rivaroxaban compared with warfarin [65].

\section{Apixaban}

Apixaban was compared with warfarin in the Apixaban for Reduction in Stroke and Other Thromboembolic Events in Atrial Fibrillation (ARISTOTLE) study [12] and with aspirin in patients deemed intolerant of warfarin in the Apixaban Versus Acetylsalicylic Acid to Prevent Stroke in Atrial Fibrillation Patients Who Have Failed or Are Unsuitable for vitamin K Antagonist Treatment (AVERROES) study [47]. The dose of apixaban was reduced from $5 \mathrm{mg}$ bid to $2.5 \mathrm{mg}$ bid in participants who had a serum creatinine concentration $\leq 1.5 \mathrm{mg} / \mathrm{dl}$ $(133 \mu \mathrm{mol} / \mathrm{l})$ and either age $\geq 80$ years or a body weight $\leq 60 \mathrm{~kg}$ in both studies. When compared against warfarin, apixaban was more effective in reducing strokes and all-cause mortality and had a lower risk of major bleeding with no significant age interaction [12]. Those participants with at least moderate renal impairment $(\mathrm{eCrCl} 25-50 \mathrm{ml} / \mathrm{min})$ had half the rate of major hemorrhage with apixaban (3.3\%) versus warfarin (6.7\%) [66]. 
When compared with aspirin in patients deemed unsuitable for warfarin in the AVERROES study, apixaban was superior to aspirin in preventing stroke or systemic embolism in patients with AF, including those aged $\geq 75$ years [47]. There was no significant increase in risk of major bleeding in patients $\geq 75$ years. In addition, there was no significant difference in the risk of major bleeding in patients with stage $3 \mathrm{CKD}$. The results of the AVERROES study have significant implications for at least $30 \%$ of patients who are considered ideal candidates for anticoagulation therapy and are at risk of stroke, but are not on warfarin [67]. This is particularly relevant in the elderly as over $50 \%$ of patients $\geq 75$ years who are at risk of strokes due to AF are not on anticoagulation therapy [26, 48].

\section{Comparisons Between Novel Oral Anticoagulants}

The use of novel anticoagulants to reduce stroke risk in patients remains an exciting avenue for further study. The differences in trial populations between individual trials with differing dosing regimens and lack of head-tohead comparisons combine to prevent reliable comparisons between novel agents. Indirect comparisons may be misleading, as the populations were not homogenous. ROCKETAF included a population at high risk of stroke compared with the RE-LY and ARISTOTLE studies. In addition, the time in therapeutic range achieved in the warfarin arm of the ROCKET-AF study was lower than in RE-LY and ARISTOTLE. Aspirin use could have affected the safety and efficacy of the novel agents and was lowest in ARISTOTLE (30.9\%) [12] (vs. $39.7 \%$ in RE-LY (39.7\%) [10] and 36.5\% in ROCKET-AF [11]).
Based on our analysis of available evidence, apixaban (ARISTOTLE dosing schedule), rivaroxaban (ROCKET-AF dosing schedule) and dabigatran $150 \mathrm{mg}$ bid are all superior to therapeutic warfarin anticoagulation for reduction in stroke and systemic embolism in patients with $\mathrm{AF} \geq 75$ years old. The relative risk reduction for stroke or systemic embolism with these new oral anticoagulants averages about $30 \%$. This translates to a number needed to treat of about 150 elderly AF patients per year to prevent one stroke or systemic embolism with novel anticoagulants compared with warfarin. Major hemorrhage rates are similar or reduced by novel oral anticoagulants compared with warfarin in elderly AF patients; an exception to this is high-dose dabigatran, which is associated with a major increase in gastrointestinal bleeding, but a significant reduction in intracranial hemorrhage relative to warfarin.

\section{CONCLUSIONS}

The prevalence and importance of AF is increasing with an aging population. Oral anticoagulants are effective at reducing the absolute risk of ischemic stroke compared with antiplatelet agents in elderly patients, but are associated with increased risk of hemorrhage. However, the risk of extracranial hemorrhage is overshadowed by the absolute reduction in risk of stroke in most elderly patients. Novel anticoagulants, dabigatran, rivaroxaban and apixaban, are at least as effective as warfarin in reducing the risk of stroke and are safer in elderly patients than warfarin. These agents are also easier to use and unlike warfarin do not require frequent blood test monitoring. The use of novel anticoagulant agents will likely increase as these agents are better tolerated than warfarin in the elderly. While more 
expensive compared with warfarin, the absolute economic costs remain uncertain. The greater use of anticoagulation with either warfarin or these novel agents will reduce the risk of ischemic stroke in elderly patients. As more novel anticoagulants such as edoxaban come to market, direct randomized comparisons of the novel agents will be necessary to delineate clear roles for the individual agents. Currently, recent trials of novel anticoagulants have challenged whether warfarin should be the preferred anticoagulant option for elderly patients. The novel anticoagulants are clearly effective for use in elderly patients with AF in clinical trials and should be strongly considered when anticoagulation is indicated.

\section{ACKNOWLEDGMENTS}

Drafting of manuscript: Dr Kuan Huei Ng. Critical revision of the manuscript for important intellectual content: Dr Kuan Huei $\mathrm{Ng}$, Dr Robert G. Hart and Dr John W. Eikelboom. Dr. $\mathrm{Ng}$ is the guarantor for this article and takes responsibility for the integrity of the work as a whole. No funding or sponsorship was received for this study or publication of this article.

Conflict of Interest. Dr. Kuan Huei Ng declares no conflict of interest. Dr. Robert Hart has received consultation fees from Boehringer Ingelheim (dabigatran) and Bayer (rivaroxaban) in the past 2 years. Dr. John Eikelboom has received consulting fees and/or honoraria from Astra-Zeneca, Bayer Boehringer-Ingelheim, Bristol-Myers-Squibb, Daiichi-Sankyo, Eli-Lilly, Glaxo-Smith-Kline, Pfizer, Janssen and SanofiAventis, and grants and/or in-kind support from Astra-Zeneca, Bayer, Boehringer-Ingelheim,
Bristol-Myers-Squibb, Glaxo-Smith-Kline, Pfizer, Janssen and Sanofi-Aventis.

Open Access. This article is distributed under the terms of the Creative Commons Attribution Noncommercial License which permits any noncommercial use, distribution, and reproduction in any medium, provided the original author(s) and the source are credited.

\section{REFERENCES}

1. Go AS, Hylek EM, Phillips KA, Chang Y, Henault LE, Selby JV, et al. Prevalence of diagnosed AF in adults: national implications for rhythm management and stroke prevention: the AnTicoagulation and Risk Factors in AF (ATRIA) Study. JAMA. 2001;285(18): 2370-5.

2. Hobbs FD, Fitzmaurice DA, Mant J, et al. A randomised controlled trial and cost-effectiveness study of systematic screening (targeted and total population screening) versus routine practice for the detection of AF in people age 65 years and over. The SAFE study. Health Technol Assess 2005;9;iiiiv, ix-X, 1-74.

3. National Collaborating Centre for Chronic Conditions. Stroke: national clinical guideline for diagnosis and initial management of acute stroke and transient ischaemic attack (TIA). London: Royal College of Physicians, 2008. http://www. nice.org.uk/CG68. Last Accessed June 18, 2013.

4. Mant J, Wade DT, Winner S. Health care needs assessment: stroke. Health care needs assessment: the epidemiologically based needs assessment review, first series. 2nd ed. In: Stevens A, Raftery J, Mant J, et al., editors. Oxford: Radcliffe Medical Press; 2004. p. 141-244.

5. Wolf PA, Abbott RD, Kannel WB. AF as an independent risk factor for stroke: the Framingham Study. Stroke. 1991;22:983-8.

6. Tu HT, Campbell BC, Christensen S, Collins M, De Silva DA, Butcher KS, et al. Pathophysiological determinants of worse stroke outcome in AF. Cerebrovasc Dis. 2010;30:389-95.

7. Van Walraven C, Hart RG, Connolly S, Austin PC, Mant J, Hobbs FDR, et al. Effect of age on stroke prevention therapy in patients with AF: the AF investigators. Stroke. 2009;40:1410-6. 
8. Gage BF, Boechler M, Doggette AL, Fortune G, Flaker GC, Rich MW, et al. Adverse outcomes and predictors of underuse of antithrombotic therapy in medicare beneficiaries with chronic AF. Stroke. 2000;31:822-7.

9. Eikelboom JW, Weitz JI. New anticoagulants. Circulation. 2010;121:1523-32.

10. Connolly SJ, Ezekowitz MD, Yusuf S, Eikelboom J, Oldgren J, Parekh A, et al. Dabigatran versus warfarin in patients with AF. $\mathrm{N}$ Engl J Med. 2009;361:1139-51.

11. Patel MR, Mahaffey KW, Garg J, Pan G, Singer DE, Hacke W, et al. Rivaroxaban versus warfarin in nonvalvular AF. N Engl J Med. 2011;365:883-91.

12. Granger CB, Alexander JH, McMurray JJ, Lopes RD, Hylek EM, Hanna M, et al. Apixaban versus warfarin in patients with AF. N Engl J Med. 2011;365: 981-92.

13. Benjamin EJ, Wolf PA, D'Agostino RB, Silbershatz H, Kannel WB, Levy D. Impact of AF on the risk of death: the Framingham Heart Study. Circulation. 1998;98:946-52.

14. Stroke Risk in AF Working Group. Independent predictors of stroke in patients with AF: a systematic review. Neurology. 2007;69(6):546-54.

15. Coppens M, Eikelboom JW, Hart RG, Yusuf S, Lip GYH, Dorian P, et al. The CHA2DS2-VASc score identifies those patients with AF and a CHADS2 score of 1 who are unlikely to benefit from oral anticoagulant therapy. Eur Heart J. 2013;34:170-6.

16. Marinigh R, Lip GY, Fiotti N, Giansante C, Lane DA. Age as a risk factor for stroke in AF patients implications for thromboprophylaxis: implications for thromboprophylaxis. J Am Coll Cardiol. 2010;56:827-37.

17. Gage BF, Waterman AD, Shannon W, Boechler M, Rich MW, Radford MJ. Validation of clinical classification schemes for predicting stroke: results from the National Registry of AF. JAMA. 2001;285: 2864-70.

18. Pearce LA, Hart RG, Halperin JL. Assessment of three schemes for stratifying stroke risk in patients with nonvalvular AF. Am J Med. 2000;109:45-51.

19. Cairns JA, Connolly S, McMurtry S, Stephenson M, Talajic M. Canadian Cardiovascular Society atrial fibrillation guidelines 2010: prevention of stroke and systemic thromboembolism in atrial fibrillation and flutter. Canad J Cardiol. 2011;27(1):74-90.

20. Camm AJ, Kirchhof P, Lip GYH, Schotten U, Savelieva I, Ernst S, et al. Guidelines for the management of atrial fibrillation: the Task Force for the Management of Atrial Fibrillation of the European Society of Cardiology (ESC). Eur Heart J. 2010;31(19):2369-429.

21. Lip GYH, Nieuwlaat R, Pisters R, Lane DA, Crijns HJ. Refining clinical risk stratification for predicting stroke and thromboembolism in AF using a novel risk factor-based approach: the Euro Heart Survey on AF. Chest. 2010;137:263-72.

22. Olesen JB, Lip GYH, Hansen ML, Hansen PR, Tolstrup JS, Lindhardsen J, et al. Validation of risk stratification schemes for predicting stroke and thromboembolism in patients with AF: nationwide cohort study. BMJ. 2011;342:d124.

23. Atrial Fibrillation Investigators. Risk factors for stroke and efficacy of antithrombotic therapy in AF. Analysis of pooled data from five randomized controlled trials. Arch Intern Med. 1994;154:1449-57.

24. Friberg L, Benson L, Rosenqvist M, Lip GYH. Assessment of female sex as a risk factor in AF in Sweden: nationwide retrospective cohort study. BMJ. 2012;344:e3522.

25. Hart RG, Eikelboom JW, Pearce LA. Sex, stroke, and AF. Arch Neurol. 2012;69:1641-3.

26. Simpson CR, Wilson C, Hannaford PC, Williams D. Evidence for age and sex differences in the secondary prevention of stroke in Scottish primary care. Stroke. 2005;36:1771-5.

27. European Heart Rhythm Association; European Association for Cardio-Thoracic Surgery, Camm AJ, Kirchhof P, Lip GYH, Schotten U, Savelieva I, Ernst S, et al. Guidelines for the management of AF: the Task Force for the Management of AF of the European Society of Cardiology (ESC). Eur Heart J. 2010;31:2369-429.

28. Fuster V, Rydén LE, Cannom DS, Crijns HJ, Curtis AB, Kenneth A, et al. ACC/AHA/ESC 2006 guidelines for the management of patients with $\mathrm{AF}$-executive summary. Circulation. 2006;114:700-52.

29. Go AS, Fang MC, Udaltsova N, Chang Y, Pomernacki NK, Borowsky L, et al. Impact of proteinuria and glomerular filtration rate on risk of thromboembolism in AF: the anticoagulation and risk factors in AF (ATRIA) study. Circulation. 2009;119:1363-9.

30. Roderick PJ, Atkins RJ, Smeeth L, Nitsch DM, Hubbard RB, Fletcher AE, et al. Detecting chronic kidney disease in older people; what are the implications? Age Ageing. 2008;37:179-86.

31. Hart RG, Pearce LA, Asinger RW, Herzog CA. Warfarin in AF patients with moderate chronic 
kidney disease. Clin J Am Soc Nephrol. 2011;6:2599-604.

32. Eikelboom JW, Connolly SJ, Gao P, Paolasso E, De Caterina R, Husted S, et al. Stroke risk and efficacy of apixaban in AF patients with moderate chronic kidney disease. J Stroke Cerebrovasc Dis. 2012;21:429-35.

33. Vázquez E, Sánchez-Perales C, Lozano C, GarcíaCortés MJ, Borrego F, Guzmán M, et al. Comparison of prognostic value of AF versus sinus rhythm in patients on long-term hemodialysis. Am J Cardiol. 2003;92:868-71.

34. Hart RG, Pearce LA, Miller VT, Anderson DC, Rothrock JF, Albers GW, et al. Cardioembolic vs. noncardioembolic strokes in AF: frequency and effect of antithrombotic agents in the stroke prevention in AF studies. Cerebrovasc Dis. 2000;10:39-43.

35. Aguilar M, Hart R. Antiplatelet therapy for preventing stroke in patients with non-valvular AF and no previous history of stroke or transient ischemic attacks. Cochrane Database Syst Rev. 2005;19:CD001925.

36. National Collaborating Center for Chronic Conditions. Atrial fibrillation: national clinical guideline for management in primary and secondary care. London Royal College of Physicians, 2006. http://www.nice.org.uk/CG36. Last Accessed June 18, 2013.

37. Lip GYH, Frison L, Halperin JL, Lane DA. Comparative validation of a novel risk score for predicting bleeding risk in anticoagulated patients with AF: the HAS-BLED (Hypertension, Abnormal Renal/Liver Function, Stroke, Bleeding History or Predisposition, Labile INR, Elderly, Drugs/Alcohol Concomitantly) score. J Am Coll Cardiol. 2011;57:173-80.

38. Gage BF, Yan Y, Milligan PE, Waterman AD, Culverhouse R, Rich MW, et al. Clinical classification schemes for predicting hemorrhage: results from the National Registry of AF (NRAF). Am Heart J. 2006;151:713-9.

39. Van Walraven C, Hart RG, Singer DE, Laupacis A, Connolly S, Petersen P, et al. Oral anticoagulants vs aspirin in nonvalvular AF: an individual patient meta-analysis. JAMA. 2002;288:2441-8.

40. Chatap G, Giraud K, Vincent J-P. AF in the elderly: facts and management. Drugs Aging. 2002;19: 819-46.

41. Hylek EM, Evans-Molina C, Shea C, Henault LE, Regan S. Major hemorrhage and tolerability of warfarin in the first year of therapy among elderly patients with AF. Circulation. 2007;115:2689-96.
42. Pisters R, Lane DA, Nieuwlaat R, De Vos CB, Crijns HJGM, Lip GYH. A novel user-friendly score (HASBLED) to assess 1-year risk of major bleeding in patients with AF: the Euro Heart Survey. Chest. 2010;138:1093-100.

43. Fang MC, Go AS, Chang Y, Borowsky LH, Pomernacki NK, Udaltsova N, et al. A new risk scheme to predict warfarin-associated hemorrhage: The ATRIA (Anticoagulation and Risk Factors in AF) study. J Am Coll Cardiol. 2011;58:395-401.

44. Hart RG, Pearce LA, Aguilar MI. Meta-analysis: antithrombotic therapy to prevent stroke in patients who have nonvalvular AF. Ann Intern Med. 2007;146:857-67.

45. Mant J, Hobbs FDR, Fletcher K, Roalfe A, Fitzmaurice D, Lip GYH, et al. Warfarin versus aspirin for stroke prevention in an elderly community population with AF (the Birmingham AF Treatment of the Aged Study, BAFTA): a randomised controlled trial. Lancet. 2007;370:493-503.

46. Connolly SJ, Pogue J, Hart RG, Hohnloser SH, Pfeffer M, Chrolavicius $S$, et al. Effect of clopidogrel added to aspirin in patients with AF. N Engl J Med. 2009;360:2066-78.

47. Connolly SJ, Eikelboom J, Joyner C, Diener H-C, Hart R, Golitsyn S, et al. Apixaban in patients with AF. N Engl J Med. 2011;364:806-17.

48. Johnson CE, Lim WK, Workman BS. People aged over 75 in $\mathrm{AF}$ on warfarin: the rate of major hemorrhage and stroke in more than 500 patientyears of follow-up. J Am Geriatr Soc. 2005;53:655-9.

49. Hart RG, Tonarelli SB, Pearce LA. Avoiding central nervous system bleeding during antithrombotic therapy: recent data and ideas. Stroke. 2005;36: 1588-93.

50. Hughes M, Lip GYH. Risk factors for anticoagulation-related bleeding complications in patients with AF: a systematic review. QJM. 2007;100: 599-607.

51. Hylek EM, Go AS, Chang Y, Jensvold NG, Henault LE, Selby JV, et al. Effect of intensity of oral anticoagulation on stroke severity and mortality in AF. N Engl J Med. 2003;349:1019-26.

52. Fang MC, Chang Y, Hylek EM, Rosand J, Greenberg SM, Go AS, et al. Advanced age, anticoagulation intensity, and risk for intracranial hemorrhage among patients taking warfarin for AF. Ann Intern Med. 2004;141:745-52.

53. Levine MN, Raskob G, Landefeld S, Kearon C. Hemorrhagic complications of anticoagulant treatment. Chest. 1998;114(5 Suppl):511S-23S. 
54. Fang MC, Go AS, Hylek EM, Chang Y, Henault LE, Jensvold NG, et al. Age and the risk of warfarinassociated hemorrhage: the anticoagulation and risk factors in AF study. J Am Geriatr Soc. 2006;54:1231-6.

55. GurwitzJH, Avorn J, Ross-Degnan D, Choodnovskiy I, Ansell J. Aging and the anticoagulant response to warfarin therapy. Ann Intern Med. 1992;116:901-4.

56. Gage BF, Birman-Deych E, Kerzner R, Radford MJ, Nilasena DS, Rich MW. Incidence of intracranial hemorrhage in patients with AF who are prone to fall. Am J Med. 2005;118:612-7.

57. Man-Son-Hing M, Nichol G, Lau A, Laupacis A. Choosing antithrombotic therapy for elderly patients with AF who are at risk for falls. Arch Intern Med. 1999;159:677-85.

58. Fox KA, Piccini JP, Wojdyla D, Becker RC, Halperin JL, Nessel CC, et al. Prevention of stroke and systemic embolism with rivaroxaban compared with warfarin in patients with non-valvular $\mathrm{AF}$ and moderate renal impairment. Eur Heart J. 2011;32:2387-94.

59. Limdi NA, Beasley TM, Baird MF, Goldstein JA, McGwin G, Arnett DK, et al. Kidney function influences warfarin responsiveness and hemorrhagic complications. J Am Soc Nephrol. 2009;20:912-21.

60. Denny SD, Kuchibhatla MN, Cohen HJ. Impact of anemia on mortality, cognition, and function in community-dwelling elderly. Am J Med. 2006;119: 327-34.

61. Patel KV, Harris TB, Faulhaber M, Angleman SB, Connelly S, Bauer DC, et al. Racial variation in the relationship of anemia with mortality and mobility disability among older adults. Blood. 2007;109: 4663-70.

62. Devereaux PJ, Anderson DR, Gardner MJ, Putnam W, Flowerdew GJ, Brownell BF, et al. Differences between perspectives of physicians and patients on anticoagulation in patients with AF: observational study. BMJ. 2001;323:1218-22.

63. Kaatz S, Kouides PA, Garcia DA, Spyropolous AC, Crowther M, Douketis JD, et al. Guidance on the emergent reversal of oral thrombin and factor Xa inhibitors. Am J Hematol. 2012;87(Suppl 1):S141-5.

64. Eikelboom JW, Wallentin L, Connolly SJ, Ezekowitz M, Healey JS, Oldgren J, et al. Risk of bleeding with 2 doses of dabigatran compared with warfarin in older and younger patients with AF: an analysis of the randomized evaluation of long-term anticoagulant therapy (RE-LY) trial. Circulation. 2011;123:2363-72.

65. Halperin JL, Wojdyla D, Piccini JP, Lokhnygina Y, Manesh R. Efficacy and safety of rivaroxaban compared with warfarin among elderly patients with nonvalvular AF in the ROCKET-AF trial. Stroke. 2012;43:A148.

66. Hart RG, Eikelboom JW, Ingram AJ, Herzog CA. Anticoagulants in atrial fibrillation patients with chronic kidney disease. Nature reviews. Nephrology. 2012;8(10):569-78.

67. Birman-Deych E, Radford MJ, Nilasena DS, Gage BF. Use and effectiveness of warfarin in Medicare beneficiaries with AF. Stroke. 2006;37:1070-4. 